\title{
DIREITO GLOBAL E DESIGUALDADES: UM ESTUDO A PARTIR DO "DIREITO DOS POVOS" DE JOHN RAWLS
}

\section{GLOBAL LAW AND INEQUALITY: A STUDY FROM “THE LAW OF PEOPLES" OF JOHN RAWLS}

\begin{abstract}
MÁrcio RicARdo STAFFEN
Doutor em Direito Público pela Università degl Studi di Perugia (ItÁlia). DOUtor e Mestre em CiênCIA JuRIDICA PELA UNIVERSIDAde do Vale do Itajaí - UNIVALI. Pesquisador do Conselho Nacional de Justiça (CNJ). Coordenador do Programa de Pós-GRaduaÇÃo

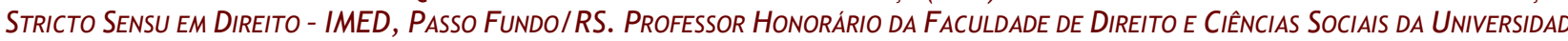
InCA GaRCilaso de La VEGa (PERU). AdVOGado (OAB/SC).

MARCIO.STAFFEN@IMED.EDU.BR

NeURo José ZAMBAM

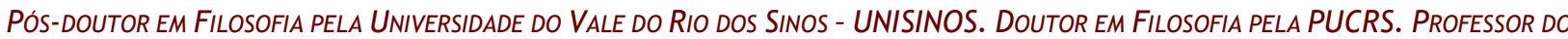

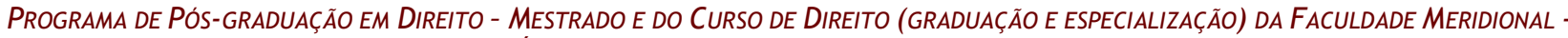

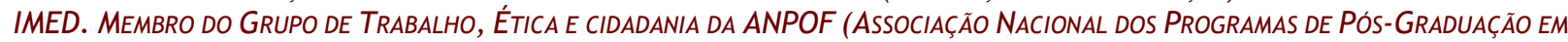
Filosofia). Pesquisador da FaCuldade Meridional. Coordenador do Grupo de Pesquisa: Multiculturalismo, minorias, esPaÇo Público E SUSTENTABILIDADE. NZAMBAM@IMED.EDU.BR
\end{abstract}

\begin{abstract}
RESUMO
As deficiências e conquistas das sociedades globalizadas impactaram a concepção, estrutura e capacidade de efetividade do direito moderno. A tradicional rigidez da norma limitada às definições territoriais do Estado nacional impede a solução de problemas supranacionais. A arquitetura das propostas jurídicas transnacionais carece de condições para sua concretização ou a estruturação de acordos com ampla participação dos líderes, das instituições e dos indivíduos. O Direito dos Povos proposto por Rawls é uma concepção de caráter global com as condições para o fortalecimento da democracia constitucional, dos Direitos Humanos e da equidade entre os povos.
\end{abstract}

Palavras-chave: Democracia; Direito dos Povos; Justiça.

\begin{abstract}
Abstract: The shortcomings and achievements of globalized societies impacted the design, structure and ability to effectiveness of modern law. The traditional rigidity of the standard limited territorial definitions of the national state prevents the solution of supranational problems. The architecture of transnational legal proposals lacks conditions for its implementation or the structuring of agreements with broad participation of the leaders, institutions and individuals. The Law of Peoples proposed by Rawls is a global character design with the conditions for the strengthening of constitutional democracy, human rights and equality among peoples.
\end{abstract}

Keywords: Democracy; The Law of Peoples; Justice. 


\section{SUMÁRIO}

INTRODUÇAO; 1 A GLOBALIZAÇÃO E O DIREITO; 2 UM DIREITO PARA TODOS OS POVOS; 3 FUNDAMENTOS PARA UM DIREITO TRANSNACIONAL; CONSIDERAÇÕES FINAIS; REFERÊNCIAS.

\section{INTRODUÇÃO}

Fazer justiça em nível internacional é um compromisso essencial do direito no atual período de exposição das diferenças, aproximação dos povos, reconhecimento dos direitos, incremento do comércio, dilemas ambientais, ameaças do terrorismo e necessidade da diminuição das desigualdades sociais e econômicas.

A estruturação do direito para responder à efetivação dos direitos fundamentais, a correção das desigualdades, ordenar as relações entre os povos, prevenir problemas e outras injustiças, representa, historicamente, a conquista da sua legitimidade e o indicativo para a avaliação das condições de justiça em suas diferentes dimensões.

As relações internacionais, considerando especialmente a melhoria das condições de transporte, a popularização das tecnologias de informação e a evolução dos inúmeros meios de comunicação com poder de aproximar povos, culturas e evidenciar interesses trouxe para a reflexão social, política, filosófica e jurídica atores até então distantes entre si ou mesmo isolados por inúmeras razões.

As desigualdades existentes no interior dos países, que foram caracterizadas por Rawls como de ordem filosófica, religiosa e moral, foram descritas, seja na sua expressão cotidiana seja nas suas condições de ordenamento social ou para a avaliação da justiça, como de difícil conciliação. Entretanto, essa é a realidade empírica, impossível de ser negada, a partir da qual é necessário fundamentar as propostas para a construção da justiça.

O contexto evidenciado anteriormente, sob semelhantes condições, repercute em nível internacional. As desigualdades têm outras características e sua repercussão tem maior amplitude, o que supõe a capacidade de conjugar interesses e busca de soluções com maior ousadia e perspicácia, assim como, o exercício da diplomacia.

Um contexto de relações diferenciadas demanda a necessidade de averiguação das necessidades, a análise cuidadosa e atenta assim como a proposição de soluções e as responsabilidades acompanhadas com a devida avaliação das possibilidades de sua efetivação.

Nesta toada, não parece crível a compreensão de que primados substanciais efetivos de justiça possam ser obtidos a partir de posições fragmentadas em cenários geopolíticos. Ocorre 
que com a consolidação de forças globalizatórias para além da economia a apresentação por demandas relativas a superação de condições justas tornou-se deveras mais facilidade, em virtude, da real proximidade dos bens em comparação e da facilidade de circulação de informações até então restritas. Não por acaso, a proposta de este artigo vir a articular justiça e desigualdade social como tópicos da pauta do Direito Global.

Com a mesma intensidade que, em nível local, os cidadãos têm o direito de perceber no seu cotidiano a concretização dos planos, programas e valores que orientam o ordenamento social, especificamente a Constituição e os princípios morais e jurídicos, assim também, nas relações globais, os povos precisam participar e ter a percepção que os ideais que dinamizam as relações entre si, oferecem as possibilidades de organização social equitativa, especificamente, a partir dos ideais democráticos de tolerância, participação, reconhecimento e aceitação dos Direito Humanos.

Este estudo visa demonstrar a necessidade de abordar os temas jurídicos relevantes para a justiça global de forma alargada, a apresentar a proposta de Rawls, especificamente na obra 'O direito dos povos' para fundamentar essa proposta, destacar as contradições e os novos cenários para a reflexão jurídica na atualidade, evidenciar a insuficiência do direito restrito aos acordos diplomáticos e institucionais para justificar e concretizar as condições de justiça e equidade, destacar os limites da compreensão do estado nacional e territorial considerando o atual estágio de desenvolvimento, das relações internacionais e do acelerado processo de globalização.

A Teoria da Justiça de John Rawls é uma referência reconhecida para a abordagem dos temas da justiça e representa uma proposta de renovação da tradicional Teoria do Contrato Social integrada às novas configurações contemporâneas. A concepção de justiça tem sido reconhecida desde a sua publicação de Uma Teoria da Justiça em 1971, ainda sob as preocupações da Guerra Fria, das deficiências e do valor da democracia, da insuficiência do utilitarismo e da existência das desigualdades presentes nas sociedades contemporâneas.

'O direito dos povos' é a explicitação da sua proposta original, porém ampliada para a construção de um modelo de justiça internacional, destinado a todos os povos. Uma proposta ideal ou utópica de Contrato Social, como é explicitada por Rawls, que representa as condições de dialogar com as demais numa arquitetura razoável e com reais possibilidades de efetivação a partir de acordos e dos valores, princípios e orientações de caráter comum.

Em que pese o respeito com as construções teóricas antecedentes, a defesa de John Rawls possibilita investigar os cenários reais e a realidade, na acepção lacaniana dos termos, 
para desmistificar bases hipotéticas do Direito Internacional e que não se coadunam com o estágio atual das relações transnacionais e globais, sobretudo, por partir do pressuposto de que o contratualismo puro não responde substancialmente ao estado d'arte de assimetrias contemporaneamente produzidas e/ou reproduzidas. Assim, cabe ao Direito Global, pelos caracteres que the são peculiares instituir um espaço de consensualidade não utópico e de respostas atuais para os problemas destes dias.

A eleição de uma obra prioritária é um recurso metodológico pra, a partir desse referencial dialogar de forma crítica com outras posições de igual teor e repercussão e, de forma integrada, abordar dados empíricos, analisar outras visões, resguardar a liberdade dos investigadores e compor um conjunto de argumentos para a fundamentação e explicitação do pensamento em questão, seja moral ou jurídico.

\section{A GLOBALIZAÇÃO E O DIREITO}

Em resumo, breve e antecipado, o Direito enquanto construção social aplicada, tem como condição primeira a procura de instrumentos de limitação dos poderes, sobretudo. Já não é mais apenas meio de ordenação social. Com isso, necessita guardar em seu bojo uma perspectiva de dever-ser, de funcionalidade social. O surgimento de novas matrizes de poder exige um novo direito de contenção dos excessos e projeção de expectativas realizáveis em um futuro próximo.

Intacto neste processo de autoafirmação não restou o ordenamento jurídico. Afinal, conforme adverte Cotterrell ${ }^{1}$, o ordenamento jurídico não será relevante a menos que a lei (em sentindo amplo) seja capaz de produzir efeitos na sociedade. Destaque-se a não tão-somente impotência jurídica como causa deste inadimplemento, some-se neste quadro os vultos impeditivos e/ou promocionais decorrentes de condições nacionais, regionais, internacionais ${ }^{2}$, tecnológicas, sociais e, especialmente, econômicas.

Notadamente os processos de globalização de maneira crescente criaram um mercado mundial, uma nova ordem supra e transnacional que permite a livre circulação de capitais, mercadorias, bens e serviços. Fez-se espaço para o exercício de um poder hegemônico de

\footnotetext{
${ }^{1}$ COTTERRELL, Roger. Law, culture and society. Aldershot: Ashgate, 2006.

2 Sobre tais circunstâncias ver: REPOSO, Antonio. Introduzione allo studio del diritto costituzionale e pubblico. PEGORARO, Lucio; REPOSO, Antonio; RINELLA, Angelo; SCARCIGLIA, Roberto; VOLPI, Mauro. Diritto costituzionale e pubblico. 3 ed. Torino: G. Giappichelli, 2009, p. 24 e ss.
} 
natureza técnico, econômico e financeiro espraiado planetariamente, o qual demonstra a redução (crise) do Estado $^{3}$ e institui instrumentos de governança global.

Contudo, o transnacionalismo não se restringe às fileiras de uma operação internacional arquitetada plenamente pela autonomia da vontade, inclusive na possibilidade de se escolher uma regra de direito, como pensou no início Philip Jessup ${ }^{4}$.

A partir da fragilidade dos tradicionais atores nacionais e internacionais de cunho público, espaços de debilidade passa(ra)m a serem ocupados, notadamente após a Segunda Guerra, por interesses transnacionais constituídos através de instituições novas, de difícil caracterização à luz do glossário político-jurídico Moderno ${ }^{5}$. A tradicional homogeneidade no pensamento político-jurídico fora perdida. Em maior ou menor medida instalou-se um cenário de tensão institucional, no qual as "velhas" instituições estatais e, por via idêntica os indivíduos, deparam-se com sensações de turbulência. ${ }^{6}$

0 poderio dos ordenamentos jurídicos estatais de produzir o próprio Direito em forma absoluta está gradualmente se redimensionando, reformulando a própria categoria histórica e política da soberania nacional na direção de uma caracterização ainda de híbrida matriz. 0 transnacionalismo jurídico está dividido em dois níveis: o primeiro e mais raso que se preocupa com os assuntos nacionais (internos) de cada Estado; e o segundo, mais amplo, diluído no cenário transnacional, constituído por uma área global ${ }^{7}$, de modo que predomine a cooperação (partnership) entre seus agentes em seu duplo nível.

Tal qual se manifestou Günther Teubner $^{8}$ a força motriz do Direito já não é mais os anseios de limitação jurídica dos poderes domésticos absolutos; mas, sobremodo, a regulação de dinâmicas policêntricas relacionadas com a circulação de modelos, capitais, pessoas e

3 Merece reprodução nesta quadra a advertência de Sabino Cassese: “Infine, il transnazionalismo dell'ordine giuridico globale suggerisce cautela nel parlare di crisi dello Stato e di fuga verso il livello globale, perchè la dinamica del sistema amministrativo globale è largamente dipendente dallo Stato o da suoi frammenti." CASSESE, Sabino. Oltre lo Stato. Bari/Roma: Laterza, 2006, p. 12-13.

${ }^{4}$ JESSUP. Philip. Direito transnacional. Rio de Janeiro: Fundo de Cultura, 1965.

${ }^{5}$ STAFFEN, Márcio Ricardo; BODNAR, Zenildo; CRUZ, Paulo Márcio. Transnacionalización, sostenibilidad y el nuevo paradigma de derecho in siglo XXI. Revista Opinión Jurídica - Universidad de Medellín, v. 10, p. 159-174, 2011.

${ }^{6}$ GIUDICE, Alessio lo. Istituire il postnazionale. Identità europea e legittimazione. Torino: G. Giappichelli, 2011.

7 CASSESE, Sabino. Oltre lo Stato. Em complemento: “Il diritto globale, quindi, non si forma solo attraverso un processo di diffusione unidirezionale, dal livello superiore al livello inferiore (top-dwn approach), ma anche com un percorso inverso, che procede dal basso verso l'alto (bottom-up approach). Le norme nazionali possono essere recipete e «risalise» a livello sovranazionale". CASSESE, Sabino. II diritto globale. Giustizia e democrazia oltre lo stato. Torino: EINAUDI, 2009, p. 125.

${ }^{8}$ TEUBNER, Gunther et alii. Transnational governance and constitucionalism. Oxford: University Oxford Press, 2004. 
instituições em espaços físicos e virtuais. E aqui encontram-se o Direito Internacional Público em vias de insuficiências potencializadas. Afinal, ao tempo em que a máxima fundante da soberania entra em colapso, o mesmo se vislumbra com atributos clássicos de autoridade e capacidade de representação jurídica adequada aos anseios sociais e individuais.

Nesta medida, necessário se faz reconsiderar as relações existentes entre Direito e Estado, entre público e privado, entre os diferentes cenários jurídicos e as autoridades legais, sob pena da exaustão dos modelos decorrentes de fraturas infindáveis. Com efeito, na dinâmica de emergência que se apresenta, imperioso o estabelecimento de rupturas elementares para superação do esquema nuclear Constituição-Estado; desfazer-se das teorias e das práticas cultivadas em "momentos" isolados, únicos e exclusivos para se mirar uma teia de coligações complexas e de variados sentidos com a análise de uma circulação multipolar de instituições ${ }^{9}$.

Nesta quadra, importante retomar uma abordagem já principiada: o sistema multilevel que orienta este complexo Direito Global. Todavia, o foco não pode se restringir apenas na existência de fluxos de relacionamento entre Estados e agentes transnacionais, como que se tal operação se procedesse sempre de modo direto e claro, o que instituiria um sistema dualevel. Em certa medida isto se deve ao fato de que as forças transnacionais escancararam com a máxima de igualdade entre os Estados no âmbito das relações internacionais e do Direito Internacional. Sob este viés não faz sentido crer que a China, com uma população superior a 1,3 bilhão de habitantes equivale a Pitcairn e sua população de 51 indivíduos ${ }^{10}$. 0 mesmo pode ser dito sobre as disparidades econômicas estampadas nos dados do PIB. Por oportuno vale mencionar que tal sistema multilevel não decorre de uma partícula nuclear originária, tal qual o Estado, no paradigma da modernidade. O nacional, o internacional e o supranacional passam a coabitar um campo de circulação de modelos em rede com tessituras horizontais, verticais, diagonais e afins.

\section{UM DIREITO PARA TODOS OS POVOS}

A necessidade de estruturação de um modelo de relações entre os povos que contemple os campos jurídicos, diplomáticos e de inúmeras áreas que impactam diretamente sobre as

\footnotetext{
${ }^{9}$ CANOTILHO, José Joaquim Gomes. "Brancosos" e interconstitucionalidade. Itinerários dos discursos sobre a historicidade constitucional. Coimbra: Almedina, 2008, p. 283.

${ }^{10}$ STAFFEN, Márcio Ricardo. Interfaces do direito global. Rio de Janeiro: Lumen Juris, 2015.
} 
diversas áreas das relações entre os povos torna-se iminente quanto mais próxima às demandas, conflitos e prerrogativas da realidade.

O objetivo do conjunto da Teoria da Justiça como Equidade no seu conjunto contempla essa pluralidade característica das sociedades contemporâneas, conforme foi destacado por Rawls: “A justiça como equidade tem por objetivo descobrir uma base pública de justificação no que se refere à questões de justiça política, dado o fato do pluralismo razoável ${ }^{11 " ”}$.

Tradicionalmente, as relações entre os povos tiveram com preocupação prioritária a construção da paz e para isto é fundamental a solução de conflitos que viessem a causar guerras. Contudo, quando a guerra fosse inevitável, após a seu término os esforços deveriam ser empenhados em vista da reconciliação, do restabelecimento das relações diplomáticas ou da compensação por excessos ou outras ações sem legitimidade.

A proposta do "Direito dos Povos" está ancorada no reconhecimento das diferenças que caracterizam as relações internacionais, ou entre os povos, que desafiam tanto os responsáveis oficiais pela diplomacia, quanto os demais em vista da paz e da construção de relacionamentos justos. Afirmamos nessa reflexão a impossibilidade de negar, excluir ou mesmo eliminar as diferenças como traço permanente das relações entre os povos. Essa característica pode limitar, orientar e, até mesmo, impossibilitar a estruturação e a efetivação do direito dos povos, entretanto é com essa dinâmica os líderes, representantes e grupos precisam estabelecer as condições para a construção do direito dos povos e, especialmente, as condições e possibilidades para a sua efetivação. A justificativa de adotar o termo povos eu invés de Estado, segundo Rawls,

[...] tem a intenção de enfatizar essas características singulares dos povos como distintas dos Estados, tal como tradicionalmente concebidos, e destacar o seu caráter moral e a natureza razoavelmente justa, ou decente de seus regimes. É significativo que os direitos e deveres dos povos no que diz respeito à sua chamada soberania derivam do próprio Direito dos Povos, com os quais concordariam juntamente com outros povos em circunstâncias adequadas. Como povos justos ou decentes, as razões para a sua conduta estão de acordo com os princípios correspondentes. Não são movidos unicamente pelos seus interesses prudentes ou racionais, as chamadas razões de Estado. ${ }^{12}$

\footnotetext{
${ }^{11}$ RAWLS, John. O liberalismo político. 2. ed. Tradução de Dinah de Abreu Azevedo. São Paulo: Ática, 2000b, p. 146

${ }^{12}$ RAWLS, John. 0 direito dos povos. Tradução de Luis Carlos Borges. São Paulo: Martins Fontes, 2001, p. 36.
} 
O direito dos povos proposto por Rawls é uma concepção mais ampla do que um direito internacional ${ }^{13}$. Na introdução da obra ${ }^{14}$, afirma a sua convicção de que é possível um direito comum aos povos que seguem determinados princípios e ideais comuns. Destaca, sobretudo, que é possível denominações diferentes para governos internos. Na conclusão dessa justificativa está a convicção de que os povos precisam ser decentes a fim de evidenciar o compromisso com princípios e políticas comuns para regular as relações mútuas.

Deriva desse convencimento a prerrogativa de conceber, mesmo sendo um ponto de vista ideal, as condições e possibilidades de uma "sociedade dos povos" bem ordenada" Entretanto, emergem situações e questões de difícil solução. 0 drama das desigualdades econômicas que compromete a curto e longo prazo a legitimidade da política, da economia e do Estado é um contrassenso e uma ameaça permanente porque impede o equilíbrio social e as relações entre os povos em muitas áreas ${ }^{16}$; as constantes ameaças à liberdade de expressão e o controle da informação; os novos modelos de imperialismo, especificamente o domínio das tecnologias e das patentes, mantém o controle de grupos sobre a coletividade, normalmente legitimadas pela legislação internacional ou pela intervenção de Estados mais poderosos sobre os demais; o comércio internacional de armas amplamente dominado pelos países membros do Conselho de Segurança das Nações Unidas ${ }^{17}$; a insegurança gerada pelo terrorismo, o racismo e a

\footnotetext{
${ }^{13} \mathrm{O}$ principal objetivo do Direito Internacional é julgar os motivos e estabelecer sanções em relação à guerra justa segundo foi destacado por Rawls (2000a, p. 418): "Ao examinar a justificativa da desobediência civil supus, para simplificar, que as leis e políticas contestadas diziam respeito a assuntos internos. É natural indagar como a teoria do direito político se aplica à política externa. Para fazê-lo é necessário estender a teoria da justiça ao direito internacional [...]. A justiça internacional é determinada pelos princípios que seriam escolhidos na posição original assim interpretada. Esses princípios são políticos, uma vez que regem políticas públicas em relação às outras nações".

${ }^{14}$ RAWLS, John. 0 direito dos povos, p. 3.

15 RAWLS (2001, p. 3) esclarece esse termo com a seguinte afirmação: “Com 'Direito dos Povos' quero referir-me a uma concepção particular de direito e justiça, que se aplica aos princípios e normas do direito e da prática internacionais".

${ }^{16}$ As denúncias sobre o aumento das desigualdades no mundo nos últimos 200 anos e as suas consequências para a economia e o equilíbrio social está exposta, com riqueza de detalhes tanto do ponto de vista histórico quanto da demonstração empírica com a exposição de dados empíricos atualizados, na pesquisa de PIKETY, Thomas. O capital no Século XXI. Tradução de Mônica Baumgarten de Bolle. Rio de Janeiro: Intrínseca, 2014. Nessa análise foi constatado o quanto a ausência ou insuficiência de dados impede análises seguras e o respectivo planejamento de ações que visem mudanças sociais.

17 Denuncia Sen (2010, p. 30), "Outra ação global, - de certa forma pouco discutida - que causa intensa miséria e privações duradouras refere-se ao envolvimento das potências mundiais no comércio globalizado de armas. Essa é uma área que requer urgentemente uma nova iniciativa global, que vá além da necessidade - muito importante de conter o terrorismo, no qual o enfoque está hoje tão pesadamente concentrado. Guerras locais e conflitos militares, que têm consequências muito destrutivas (entre as quais de abalar as perspectivas econômicas dos países pobres), utilizam-se não apenas de tensões regionais, mas também do comércio global de armamentos. 0 status quo mundial está firmemente entrincheirado nesse
} 
classificação de povos e pessoas em muitas partes do mundo impedem acordos, tratados e a construção de proposições factíveis com condições de integrar uma sociedade dos povos.

Essa configuração simultaneamente realista e marcada por contradições mereceu de Rawls a classificação em cinco tipos diferentes de sociedades nacionais a fim de demonstrar que, apesar das diferenças existentes na dinâmica das relações internacionais, existem condições para propor, negociar e consolidar a justiça em nível global. Primeiro, os povos liberais razoáveis ${ }^{18}$; segundo, os povos decentes ${ }^{19}$; terceiro, os Estados fora da lei ${ }^{20}$; quarto, sociedades sob o ônus de condições desfavoráveis ${ }^{21}$; e, quinto, absolutismos benevolentes ${ }^{22}$. As condições para a construção do Contrato Social de âmbito transnacional ou não-restrito às fronteiras nacionais, depende do efetivo engajamento dos povos, especificamente dos decentes ${ }^{23}$.

A referência para a estruturação das condições de justiça está ancorada, especialmente, num conjunto de princípios que orientam as instituições, os líderes e as instâncias mais importantes da sociedade.

tipo de negócio: os países que são membros do Conselho de Segurança das Nações Unidas forma juntos responsáveis ONU por 81\% das exportações mundiais de armas de 1996 a 2000. De fato, os líderes mundiais que expressam profunda frustração com a 'irresponsabilidade' dos ativistas antiglobalização governam os países que ganham mais dinheiro com esse tipo terrível de comércio. Os países do $\mathrm{G}^{*}$ * venderam $87 \%$ do total de armas exportadas no mundo inteiro. Somente a parte dos Estados Unidos chegou a quase $50 \%$ do total de vendas no mundo. Além disso, chega a quase $68 \%$ o total das exportações americanas de armas que foram para países em desenvolvimento".

18 "aqueles que aderem, numa maior ou menos proporção, ao modelo descrito pela justiça como equidade, portanto as democracias constitucionais ocidentais e aquelas que subscrevem aos Princípios do Estado democrático de Direito". (OLIVEIRA, Nythamar de. Rawls. Rio de Janeiro: Jorge Zahar, 2003, p. 40).

19 "povos não-liberais com uma estrutura básica que pode ser denominada 'hierarquia de consulta decente', na medida em que não negam os direitos humanos, mas os reconhecem e os protegem, inclusive permitindo aos seus cidadãos o direito de serem consultados ou um papel substancial nas decisões". (Oliveira, Nythamar de. Rawls, p. 40).

20 "regimes que se recusam a aquiescer a um direito dos povos razoáveis. Recorrendo à guerra e ao terrorismo para promover seus interesses não-razoáveis". (Oliveira, Nythamar de. Idem, p. 40).

21 "aquelas cujas circunstâncias históricas, sociais e econômicas tornam difícil, se não impossível, alcançar um regime bem-ordenado". (Oliveira, Nythamar de. Rawls, p. 40).

22 "povos que honram os direitos humanos mas negam aos seus membros um papel significativo nas decisões políticas". (Oliveira, Nythamar de. Rawls, p. 40).

${ }^{23}$ Os povos decentes são aqueles que cumprem razoavelmente as exigências de direito e justiça política, têm uma hierarquia de consulta decente. Entende Rawls que o conjunto de povos liberais são decentes e podem compor uma sociedade dos povos bem-ordenada. Os demais, "honram os direitos humanos mas, porque é negado aos seus membros um papel significativo nas decisões políticas, não são bem-ordenados". (RAWLS, John. 0 direito dos povos, p. 4-5). 
“1- Os povos são livres e independentes, e a sua liberdade e independência devem ser respeitadas por outros povos.

2- Os povos devem observar tratados e compromissos.

3- Os povos são iguais e são partes em acordos que os obrigam.

4- Os povos sujeitam-se ao dever de não-intervenção.

5- Os povos têm o direito de autodefesa, mas nenhum direito de instigar a guerra por outras razões que não à autodefesa.

6- Os povos devem honrar os direitos humanos.

7- Os povos devem observar certas restrições especificadas na conduta da guerra.

8- Os povos têm o dever de assistir a outros povos vivendo sob condições desfavoráveis que os impeçam de ter um regime político e social justo ou decente ${ }^{24}$."

A compreensão sobre a atualização da Justiça Internacional em vista de um Direito dos Povos preenche lacunas históricas que marcaram negativamente as relações entre os países e cujas consequências permanecerão por longos períodos, de outra banda, integra as demandas da atualidade. A proposta de Rawls fomenta o debate, seja pelo seu caráter inovador, seja pela sua visão utópico-realista, assim como, pelo lastro da sua fundamentação. Esse é um contexto que conjuga necessidades políticas, interesses e metas individuais, compromissos de governos, governantes, instituições e organizações em vista da justiça nas relações entre os povos. A insuficiência e, até, a pequenez do Estado Nacional, simbolizados na quebra das fronteiras culturais e políticas, e a consagração da democracia como o regime de poder do povo e suas representações, implica a necessária participação de todos na construção de uma nova ordem de relações mais ampla e eficaz em relação àquela orientada pela diplomacia oficial ou por representantes e executivos das organizações mais importantes e influentes.

A consagração dos tradicionais princípios e valores da humanidade e da democracia, especificamente, a tolerância, a participação, a entre ajuda e o respeito à dignidade humana, entre outros, clama pela sua atualização e a introdução de novos referenciais a fim de explicitar e dinamizar as razões da justiça e sua percepção no cotidiano das pessoas e do funcionamento da sociedade.

${ }^{24}$ RAWLS, John. 0 direito dos povos, p. 47. 


\section{FUNDAMENTOS PARA UM DIREITO TRANSNACIONAL}

Nestes termos, a dimensão global do Direito não busca promover a erradicação do Estado e de seus espaços de governo. Não lhe interessa também um encadeamento vertical dos entes. Todavia, o que se percebe é a real impossibilidade de cisões entre espaços nacionais, internacionais e transnacionais, como se pretendeu articular no passado com a díade nacionalinternacional ${ }^{25}$. A causa central desta projeção é a indiscutível capacidade reinante nas organizações provenientes dos fluxos globalizatórios de relacionarem-se diretamente com os sujeitos e com a sociedade civil, sem perpassar estâncias oficiais de poderes.

Promove-se, destarte, o cambiamento do modo tradicional de pensamento das instituições para um contexto de conectividade horizontal dos sistemas jurídicos, criando linkages $^{26}$, um paradigma suportado pela credibilidade em networks, verdadeiro regime complex. Por consequência, em definitivo deixa de ser importante o foco no divórcio entre o público e o privado, em virtude da dinâmica motriz impulsionadora.

Todavia, renasce frequentemente a inquirição sobre os instrumentos de respeito às normas, afinal no campo doméstico (nacional) impera a definitividade das decisões e a soberania decorrente do exercício legitimo da força pelo poder, contudo, os cenários transnacionais não gozam desta prerrogativa. Assim, como consequência deste panorama de linkages, o que se observa é a observância das normas através de instrumentos de indução e substituição, de modo que conteúdos jurídicos estanques são incluídos em pautas combinadas, isto é, a temática ambiental, por exemplo, já não se inscreve apenas pela tutela pura do ambiente, mas também em expedientes outrora tipicamente negociais e comerciais.

Além disso, os Estados passam a se sujeitarem aos expedientes globais no intuito de reduzir chances de retaliações e denúncias com consequências perniciosas e de difícil contenção. Neste contexto, o atual lamaçal no qual se encontra a Argentina é ilustração concreta da condução à crise por expedientes e agentes totalmente inéditos nos tradicionais mecanismos de resolução de conflitos.

Outro expediente novo que se observa é o surgimento de instrumentos para respeito à norma manejados na contramão dos métodos estatais clássicos, ou seja, ao invés da sanção pelo

\footnotetext{
${ }^{25}$ STAFFEN, Márcio Ricardo. A redução do estado constitucional nacional e a ascensão do direito global! Há espaço para os Juizados Especiais Federais?. ROSA, Alexandre Morais da; STAFFEN, Márcio Ricardo. Direito global: transnacionalidade e globalização jurídica. Itajaí: Universidade do Vale do Itajaí, 2013, p. 74-90.

${ }^{26}$ LEEBRON, David W. Linkages. American Journal of International Law. Yale: v. 96, 2002, p. 05.
} 
descumprimento, o rumo é alterado pela promoção direta dos sujeitos que voluntariamente adimpliram suas obrigações de modo que os reticentes se inserem em uma posição de ampla exclusão. Neste quadro, bons exemplos podem ser extraídos da articulação encabeçada pela IATA - Associação Internacional de Transportes Aéreos, com entes governamentais, empresas privadas e companhias aéreas, no caso do direito à alimentação, como Direito Humano elementar, entre FAO, GATT, importadores e exportadores de matérias agropecuárias, arquitetando verdadeiras cláusulas sociais em relações transnacionais, ou ainda, o papel da rede hoteleira Sabena durante o genocídio em Ruanda.

Nestes novos cenários, não seria de todo hábil imaginar que as bases típicas de democracia pudessem seguir seu curso pela história de modo inalterável. A articulação desta complexa network multilevel faz com que a democracia representativa não represente mais a pluralidade de demandas e anseios. Verte um processo democrático de progressivo debate e participação nos expedientes decisionais. O eixo tradicional em torno do comando e do controle carece adição de novas tensões; vertentes em lugares antes indiferentes, como é o caso da mobilização pela primavera árabe, "\#palestinefree” ou, então, o movimento "Ocupe Wall Street".

A afirmação da democracia em sede de transnacionalismo ganha novas cores na medida em que o primado da transparência passa a ocupar predominância em múltiplas práticas administrativas e judiciais, de modo a propiciar o imediato acompanhamento dos atos em constituição. Critérios de publicidade não se apresentam como suficientes na atual perspectiva. 0 primado pelo acesso à informação e medidas de transparência busca transcender ao dever de publicidade, de modo que se permitam a adequação do ordenamento jurídico nacional com a globalização jurídica. Análise rápida das decisões de grande parte das instituições transnacionais (mais de 2.000) demonstra a repressão aos dados restritos e que causam incertezas sobre seu teor.

Contudo, fato irretocável é a inexistência de uma autoridade global suprema, aos moldes do paradigma nacional e das tradições institucionais judaico-cristãs. 0 advento do transnacionalismo e da globalização jurídica apresenta em sua essência traços de consensualidade, na faceta de contratos, acordos, cooperações, mútuo reconhecimento nos expedientes de produção normativa e, por sua vez, negociações, mediações, conciliações e arbitragem para a resolução das controvérsias. Ainda que se possam elencar instituições transnacionais para resolução de pretensões resistidas, aos moldes de tribunais, todavia, sua constituição não escapa dos convênios marcos, ou seja, da consensualidade. 
Nesta quadra, importante abrir uma brecha para a análise de categoria relegada em plano inferior em comparação à governança. Trata-se justamente da relevância a ser atribuída à consensualidade, enquanto mecanismo decisional interessado na não-ocorrência de contestação da solução pelas partes sujeitas à resolução dos conflitos, fazendo frente aos desafios da unanimidade $^{27}$. Observa-se a guinada em favor da consensualidade na Conferência das Nações Unidas sobre Comércio e Desenvolvimento.

Em contraponto, consensualidade e governança se complementam reciprocamente na medida em que colaboram para favorecer a funcionalidade desta network transnacional. Criamse procedimentos administrativos mediante acordos para governabilidade cooperativa, via coligações que mesclam o nacional com o propósito de constituir o global (transnacional) ${ }^{28}$.

Diante deste contexto, Sabino Cassese aponta que tal política global rege-se pelo domínio das networks com desenvolvimentos fluídos e alianças variáveis, vencendo aquele com maior habilidade para o estabelecimento de conexões diretas com a sociedade civil. Em síntese: minimizam-se as relações verticalizadas intermediadas pelo Estado; facilitam-se os canais de circulação de modelos jurídicos e; fomenta-se a pesquisa por funcionalidades analógicas para desafios antes domésticos ${ }^{29}$.

Assim, a globalização jurídica necessita fazer frente a problemas diversos, tais como, conflitos de uniformidade e diferenças nacionais, a concorrência de normas globais-nacionaislocais, a atribuição de competências, a regulação do capital e nortes para governança global, a promoção dos Direitos Humanos, a preservação ambiental e critérios de sustentabilidade planetária, o combate de redes criminosas, enfim, uma nova e eficaz forma de limitação de um poder de extrema fluidez, como é a ordem global atual.

Por derradeiro, o paradigma de Direito Global que se anuncia promove elementos válidos para uma oxigenação consistente e atualizada dos ideais de direitos humanos, democracia e sustentabilidade. Potencial este que dificilmente materializar-se-ia em cenários de onipotência estatal, isto é, possibilita-se a substancial vivência democrática, humanitária e sustentável para além do Estado. Afinal, ainda é este, o Estado, o grande demandado por violações aos direitos humanos, supressão de faculdades democráticas e travejamento à sustentabilidade.

\footnotetext{
${ }^{27}$ CASSESE, Sabino. Chi governa il mondo? Bologna: Il Mulino, 2013, p. 31.

${ }^{28}$ SLAUGHTER, Anna-Marie. Governing the global economy through government network. BYERS, M. (Org.). The rule of law in international politics. Oxford: Oxford University Press, 2000, p. 192 ss.

${ }^{29}$ CASSESE, Sabino. Chi governa il mondo?, p. 34-35.
} 


\section{CONCLUSÃO}

As contradições existentes nas relações entre os povos, seja em nível global, seja no interior dos países, seja entre os povos, representa grave e constante ameaça à estabilidade social, à ordem jurídica, ao funcionamento das instituições, à garantia e ao exercício dos direitos, à efetivação dos Direitos Humanos e à própria sobrevivência da democracia. Esse panorama contrasta com a opilência, as facilidades e os recursos disponíveis. As conquistas sem precedentes da humanidade nos últimos 200 anos apontam para inúmeros compromissos em vista da equalização das relações entre os povos, especialmente a necessidade de diminuir as desigualdades e a construção da paz.

As deficiências notadas com larga preocupação quando são propostas ações para a utilização dos recursos ambientais e naturais que visam a um modelo de desenvolvimento sustentável, especificamente, por ser de domínio mais amplo e popular, os acordos, conferências e protocolos com o objetivo de diminuir a emissão de poluentes e outros com efeitos maléficos de longo prazo, são representativos das limitações e dos interesses que envolvem pensar, propor e levar a termo propostas de justiça entre os povos.

As inúmeras situações, normalmente amparados por dados confiáveis como os expostos acima sobre o comércio de armas, que dificultam, impedem ou inibem a estruturação de um projeto amplo, legitimo e com poder de impacto nas relações entre os povos têm na sua origem o grave dilema das desigualdades e as dificuldades de compreensão sobre temas que impactam diretamente sobre a vida das pessoas e nas políticas de alcance mais amplo, por exemplo, as relações internacionais e as futuras gerações. O exemplo destacado por Sen esclarece as dificuldades dessas controvérsias. "o ponto central da controvérsia não é a globalização em si, nem o uso do mercado como instituição, mas a desigualdade no equilíbrio geral dos arranjos institucionais - que produz uma divisão muito desigual dos benefícios da globalização ${ }^{30 " . ~}$

A Ordem Jurídica Internacional precisa ancorar a sua atuação de forma alargada, integrada e com capacidade de estruturar formas de solução dos conflitos, de prevenção e de relacionamento não dependentes dos tradicionais acordos formais e de tribunais morosos e sem

\footnotetext{
${ }^{30}$ SEN, Amartya; KLIKSBERG, Bernardo. As pessoas em primeiro lugar: a ética do desenvolvimento e os problemas do mundo globalizado. Tradução de Bernardo Ajzemberg e Carlos Eduardo Lins da Silva. São Paulo: Companhia das letras, 2010, p. 32.
} 
o real compromisso com a ordem democrática. A democracia é um sistema possível para todos os povos e para as diversas formas de organização política.

Entretanto, limitar a democracia a um conjunto de regras e normas logicamente ordenadas representa a caducidade de um sistema e a sua incapacidade de renovação. Mais importante do que regras é o conteúdo e a concretização da razão pública da democracia. As condições de justiça no atual contexto dependem das condições e das possibilidades de conjugação dos interesses, da disposição pública e das possibilidades de concretização em nível oficial e no cotidiano dos povos de acordos sobre temas relevantes como o comércio de armas, as politicas de sustentabilidade o combate ao terrorismo, o tráfico de pessoas e as regras de comércio.

A humanidade tem direito a uma ordem social e jurídica confiável. A queda da quase totalidade das fronteiras nacionais retrata a insuficiência e, por vezes a falência, do Estado Nacional como mediador dos conflitos entre os povos e organizador do funcionamento das sociedades. Um Contrato Social atualizado e com condições de integrar os novos atores e temas da atualidade se impõe.

\section{REFERÊNCIAS}

CANOTILHO, José Joaquim Gomes. "Brancosos" e interconstitucionalidade. Itinerários dos discursos sobre a historicidade constitucional. Coimbra: Almedina, 2008.

CASSESE, Sabino. Oltre lo Stato. Bari/Roma: Laterza, 2006.

II diritto globale. Giustizia e democrazia oltre lo stato. Torino: EINAUDI, 2009. . Chi governa il mondo? Bologna: Il Mulino, 2013.

COTTERRELL, Roger. Law, culture and society. Aldershot: Ashgate, 2006.

GIUDICE, Alessio lo. Istituire il postnazionale. Identità europea e legittimazione. Torino: G. Giappichelli, 2011.

JESSUP. Philip. Direito transnacional. Rio de Janeiro: Fundo de Cultura, 1965.

LEEBRON, David W. Linkages. American Journal of International Law. Yale: v. 96, 2002.

OLIVEIRA, Nythamar de. Rawls. Rio de Janeiro: Jorge Zahar, 2003. 


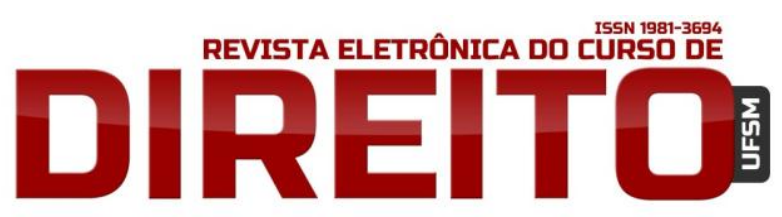

DIREITO GLOBAL E DESIGUALDADES: UM ESTUDO A PARTIR DO "DIREITO DOS POVOS" DE JOHN RAWLS

MÁRCIO RICARDO STAFFEN, NEURO JOSÉ ZAMBAM

PIKETY, Thomas. O capital no Século XXI. Tradução de Mônica Baumgarten de Bolle. Rio de Janeiro: Intrínseca, 2014.

RAWLS, John. Uma teoria da justiça. Tradução de Almiro Pisetta e Lenita M. R. Esteves. São Paulo: Martins Fontes, 2000.

Ática, 2000b.

O liberalismo político. 2. ed. Tradução de Dinah de Abreu Azevedo. São Paulo:

O direito dos povos. Tradução de Luis Carlos Borges. São Paulo: Martins Fontes,

2001.

REPOSO, Antonio. Introduzione allo studio del diritto costituzionale e pubblico. PEGORARO, Lucio; REPOSO, Antonio; RINELLA, Angelo; SCARCIGLIA, Roberto; VOLPI, Mauro. Diritto costituzionale e pubblico. 3. ed. Torino: G. Giappichelli, 2009.

SEN, Amartya; KLIKSBERG, Bernardo. As pessoas em primeiro lugar: a ética do desenvolvimento e os problemas do mundo globalizado. Tradução de Bernardo Ajzemberg e Carlos Eduardo Lins da Silva. São Paulo: Companhia das Letras, 2010.

SLAUGHTER, Anna-Marie. Governing the global economy through government network. BYERS, M. (Org.). The rule of law in international politics. Oxford: Oxford University Press, 2000.

STAFFEN, Márcio Ricardo; BODNAR, Zenildo; CRUZ, Paulo Márcio. Transnacionalización, sostenibilidad y el nuevo paradigma de derecho in siglo XXI. Revista Opinión Jurídica Universidad de Medellín, v. 10, p. 159-174, 2011.

STAFFEN, Márcio Ricardo. A redução do estado constitucional nacional e a ascensão do direito global! Há espaço para os Juizados Especiais Federais?. ROSA, Alexandre Morais da; STAFFEN, Márcio Ricardo. Direito global: transnacionalidade e globalização jurídica. Itajaí: Universidade do Vale do Itajaí, 2013, p. 74-90.

STAFFEN, Márcio Ricardo. Interfaces do direito global. Rio de Janeiro: Lumen Juris, 2015.

TEUBNER, Gunther et alii. Transnational governance and constitucionalism. Oxford: University Oxford Press, 2004.

Recebido em: 26.08.2015 / Aprovado em: 21.09.2015 